\title{
Rancang Bangun Sistem Informasi Service Reservation Berbasis Android (Studi Kasus : Bengkel Bintang Motor Palembang)
}

\author{
Irfan Dwi Jaya, Muhamad Kadafi, dan Riska Novialita Mustar
}

\begin{abstract}
PT Bintang Mulia Jaya is one of the companies engaged in retail of Honda motorcycle, as for problems in the field of maintenance that is often the occurrence of motorcycle queue to be repaired, the service has been full and lack of mechanic power than the number of customer queues. The purpose of this research is to build an information system of motorcycle service reservation based on android in Bengkel Bintang Motor of Palembang, in order to facilitate the customer to order service that can manage customer data, technician data, service data, sparepart data, transaction data, booking data and queue and manage Reports. Using prototype methods and using Unified Modeling Languange (UML) to visualize modeling, while programming languages use PHP, HTML5, JavaScript with MySQL for database processing. Use Apache Cordova as an android mobile application platform. This research produces customer data, technician data, service data, sparepart data, transaction data, booking data and queue and can assist in manage reports.
\end{abstract}

Index Terms-Information System, Reservation, Android, Cordova.

Abstrak--PT Bintang Mulia Jaya adalah salah satu perusahaan yang bergerak di dalam bidang retail sepeda motor honda, adapun masalah dalam bidang perawatan yaitu sering terjadinya penumpukan antrian sepeda motor yang akan diperbaiki, layanan yang telah penuh serta kurangnya tenaga montir dibandingkan banyaknya antrian pelanggan. Tujuan penelitian ini untuk membangun sistem informasi service reservation motor berbasis android di bengkel bintang motor palembang agar mempermudah para customer untuk melakukan pemesanan layanan service yang dapat mengelola data pelanggan, data teknisi, data service, data saprepart, data transaksi, data booking dan antrian serta mengelola laporan menggunakan metode prototype dan

Irfan Dwi Jaya, Sistem Informasi, Universitas Islam Negeri Raden Fatah Palembang; email : irfan_dj@radenfatah.ac.id

Muhamad Kadafi, Sistem Informasi, Universitas Islam Negeri Raden Fatah Palembang, email : kadafi_uin@ radenfatah.ac.id

Riska Novialita Mustar, Sistem Informasi, Universitas Islam Negeri Raden Fatah Palembang; email : riskamustar@gmail.com menggunakan Unified Modeling Languange (UML) untuk memvisualisasikan pemodelan, sedangkan bahasa pemrograman menggunakan PHP, HTML5, JavaScript dengan MySQL untuk pengolahan databasenya. Menggunakan Apache Cordova sebagai platform aplikasi mobile android. Penelitian ini menghasilkan data pelanggan, data teknisi, data service, data sparepart, data transaksi, data booking dan antrian serta dapat membantu dalam pengelolahan laporan.

Kata Kunci- Sistem Informasi, Reservasi, Android, Cordova.

\section{PENDAHULUAN}

$\mathrm{K}$ endaraan saat ini menjadi idola, baik dari kalangan masyarakat menengah kebawah sampai dengan kalangan masyarakat menengah keatas. Kendaraan merupakan alat transportasi yang menjadi ujung tombak dari segala kegiatan yang dilakukan semua kalangan. Khususnya kendaraan dengan jenis sepeda motor, dimana kendaraan jenis ini merupakan kendaraan yang paling banyak diminati dikarenakan dari sisi harganya yang terjangkau oleh semua kalangan masyarakat. Selain itu juga dalam segi perawatan atau service sepeda motor tidak harus memerlukan biaya yang besar.

Service atau kata lain tune up adalah pekerjaan yang meliputi perawatan, pemeriksaan, penyetelan dan penggantian komponen motor yang telah mengalamai keausan atau telah rusak seiring dengan berjalannya waktu pemakaian[1]. Service rutin diperlukan untuk menjaga peforma mesin motor agar selalu dalam kondisi yang prima. Sepeda motor yang digunakan secara rutin atau terus-menerus akan mengakibatkan bagian dari sepeda motor tersebut seperti mesin, transmisi, rangka, dsb akan mengalami kelelahan dan keausan sehingga mengurangi kinerjanya. Sehingga sepeda motor harus dilakukan service secara berkala.

PT Mulia Jaya atau Bintang Motor adalah perusahaan yang bergerak didalam bidang retail sepeda motor khususnya sepeda motor dengan merk Honda. Aktivitas yang ada di perusahaan ini mencakup 3 bagian yaitu bidang penjualan motor $(\mathrm{H} 1)$, pemeliharan $(\mathrm{H} 2)$ dan 
suku cadang (H3). Dalam bidang pemeliharaan atau bengkel sepeda motor saat ini memiliki permasalahan yaitu sering terjadinya penumpukan antrian sepeda motor yang akan diperbaiki, layanan yang telah penuh serta kurangnya tenaga montir dibandingkan banyaknya antrian pelanggan. Masalah itu dikarenakan waktu perawatan yang lama, serta customer datang dalam waktu yang bersamaan untuk melakukan perawatan motor sehingga menyebabkan customer batal melakukan perawatan atau service. Tak hanya itu kurangnya informasi tentang pendaftaran service dan informasi harga sparepart juga menjadi kendala.

Oleh karena itu, diperlukan suatu sistem informasi service reservation yang dapat membantu pelanggan melakukan reservasi dimana pelanggan tidak perlu datang untuk melakukan pendaftaran dan pihak bengkel dapat memberikan informasi kepada pelanggan apabila kendaraan sudah selesai diperbaiki (di service)[2]. dan juga sistem ini bertujuan agar mendapatkan keefisienan dalam melakukan layanan service customer dengan dapat mengetahui biaya yang akan dikeluarkan oleh customer tanpa harus datang terlebih dahulu ke bengkel serta membantu customer melakukan pemesanan layanan service untuk hari yang mereka butuhkan. Serta sistem yang dibangun menggunakan Apache Cordova, dimana sistem dapat dikembangkan dan dipublish dalam bentuk APK agar dapat dijalankan pada smartphone[3], sehingga dapat digunakan oleh pelanggan. Menggunakan Apache Cordova juga dapat membantu pengembang dalam membangun aplikasi berbasis mobile tanpa kode asli (java dan xml untuk android)[4].

\section{LANDASAN TEORI}

A. Android

Android merupakan sistem operasi yang digunakan untuk telepon seluler yang berbasis Linux[5]. Selain merupakan sebuah sistem operasi perangkat mobile berbasis linux yang mencakup sistem operasi, middleware, dan aplikasi. Beberapa pengertian lain dari Android, yaitu:

1. Merupakan platform terbuka (Open Source) bagi para pengembang (Programmer) untuk membuat aplikasi.

2. Merupakan sistem operasi yang dibeli Google Inc, dari Android Inc.

3. Bukan bahasa pengembangan, tetapi haya menyediakan lingkungan hidup atau run time environment yang disebut DVM (Dalvik Virtual Machine) yang telah dioptimasi untuk alat/device dengan sistem memori kecil[6].

\section{B. Apache Cordova}

Apache Cordova adalah framework pengembangan open source aplikasi berbasis mobile. Dimana memungkinkan pengembang untuk membuat aplikasi mobile dengan menggunakan CSS3, HTML5 dan JavaScript[7].

Dimana dalam satu set API device Apache Cordova memungkinkan pengembang aplikasi mobile untuk mengakses fungsi perangkat asli seperti kamera, phonebook, sms, dan lain-lain[8].

\section{Unified Modeling Language (UML)}

UML merupakan sebuah standarisasi bahasa pemodelan untuk pembangunan perangkat lunak yang dibangun dengan menggunakan teknik pemrograman berorientasi objek. UML muncul karena adanya kebutuhan pemodelan visual untuk menspesifikasikan, menggambarkan, membangun, dan dokumentasi dari sistem perangkat lunak[9].

Untuk mendapatkan banyak pandangan terhadap sistem informasi yang akan dibangun, UML (Unified Modeling Language) menyediakan beberapa diagram visual yang menunjukkan berbagai aspek dalam sistem. Banyaknya diagram tersebut dimaksudkan untuk memberi gambaran yang lebih terintegrasi terhadap sistem yang akan dibangun[10].

\section{METODE PENELITIAN}

\section{Metode Pengumpulan Data}

Adapun teknik-teknik pengambilan data yang peneliti lakukan dalam penelitian adalah sebagai berikut:

a. Observasi

Observasi ini dilakukan dengan melakukan pengamatan langsung pada bengkel Bintang Motor Palembang untuk mendapatkan permasalahan serta tentang sistem yang sedang berjalan untuk diolah dalam sistem yang akan dibuat.

b. Wawancara

Wawancara dilakukan dengan mengadakan sesi tanya jawab kepada pihak yang berwenang (Front Desk, Teknisi, dan Pimpinan) untuk memberikan informasi serta dengan melibatkan beberapa karyawan yang pekerjaannya berkaitan dengan objek penelitian di bengkel bintang motor Palembang.

\section{Metode Pengembangan Sistem}

Seringkali pelanggan mendefinisikan sasaran perangkat lunak secara umum, tetapi tidak bisa mengidentifikasi spesifikasi kebutuhan yang rinci untuk fungsi dan fitur yang nantinya akan dimiliki perangkat lunak yang akan dikembangkan. Dalam hal yang lain pengembang mungkin tidak merasa pasti tentang algoritma yang digunakan dan merasa tidak pasti akan kemampuan perangkat lunak untuk beradaptasi dengan sistem operasi ataupun interaksi dengan pengguna. Sehingga pembuatan prototype memungkinkan proses pengembangan perangkat lunak dapat dikembangkan sesuai dengan spesifikasi dan kebutuhan dari pengguna.

Prototype model yaitu metode pengembangan 
perangkat lunak yang memungkinkan adanya interaksi antara pengembang sistem dengan pengguna sistem, sehingga dapat mengatasi ketidakserasian antara pengembang dan pengguna[11]. Adapun tahapan dari prototype model dapat dilihat pada gambar 1 berikut :

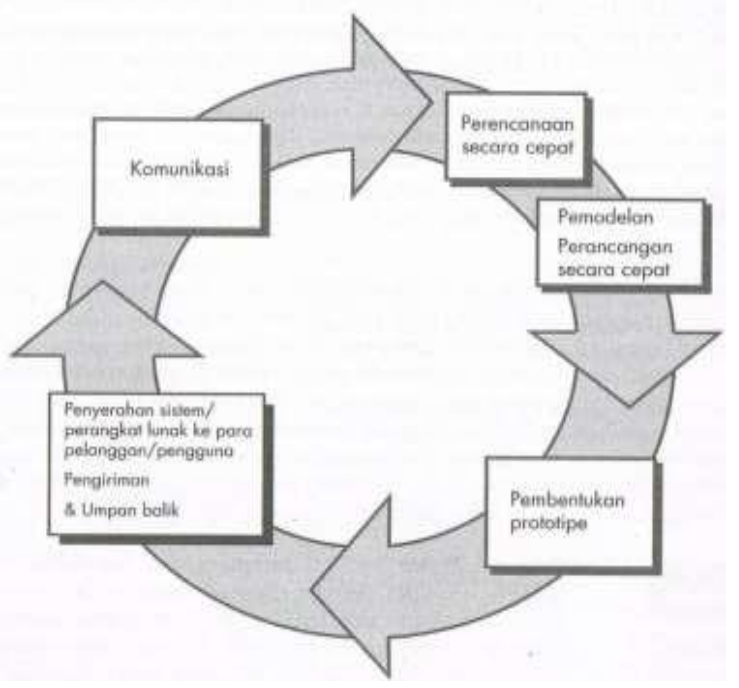

Gambar 1. Model Prototype

1. Komunikasi. Tahapan ini merupakan langkah awal dari untuk mengidentifikasi permasalahan yang ada pada bengkel Bintang Motor, serta informasi lain yang diperlukan dalam proses pengembangan sistem. Komunikasi dilakukan dengan pihak yang terkait dengan objek penelitian di bengkel Bintang motor Palembang.

2. Perencanaan. Tahapan ini untuk menentukan penjadwalan yang berkaitan dengan kegiatan penelitian mulai dari wawancara, penentuan sumber daya untuk pengembangan berdasarkan kebutuhan sistem, dan tujuan agar pengembangan dapat sesuai dengan kebutuhan sistem.

3. Pemodelan. Tahapan selanjutnya menggambarkan model sistem yang akan dikembangkan dengan menggunakan Unified Modelling Language (UML).

4. Konstruksi. Tahapan ini merupakan proses membangun sistem dengan (pengkodingan) dari rancangan sistem yang dibuat. Dimana untuk pihak bengkel akan dikembangkan aplikasi berbasis web menggunakan bahasa pemrograman PHP dan css serta javascript dan HTML5. Sedangkan untuk pelanggan akan dikembangkan aplikasi android yang diintegrasikan dengan JSON dan apache cordova.

5. Penyerahan. Untuk penyerahan sistem langsung diberikan kepada pinpinan dari PT. Mulia Jaya. Tahapan ini dibutuhkan untuk mendapatkan feedback dari pengguna, sebagai hasil evaluasi dari tahapan sebelumnya dan implementasi dari sistem yang dikembangkan.

\section{HASIL PENELITIAN}

\section{A. Sistem Yang Berjalan}

Pada sistem yang berjalan proses yang pertama kali diakukan adalah komunikasi dengan pihak bengkel. Tujuan dari komunikasi adalah untuk mengidentifikasi permasalahan-permasalahan dan mendapatkan data yang terkait. Komunikasi dilakukan menggunakan wawancara kepada pegawai di bengkel agar mendapatkan gambaran umum dari permasalahan dan pembuatan sistem.

Berdasarkan hasil komunikasi maka didapat prosedur sistem yang sedang berjalan, seperti pada gambar 2 :

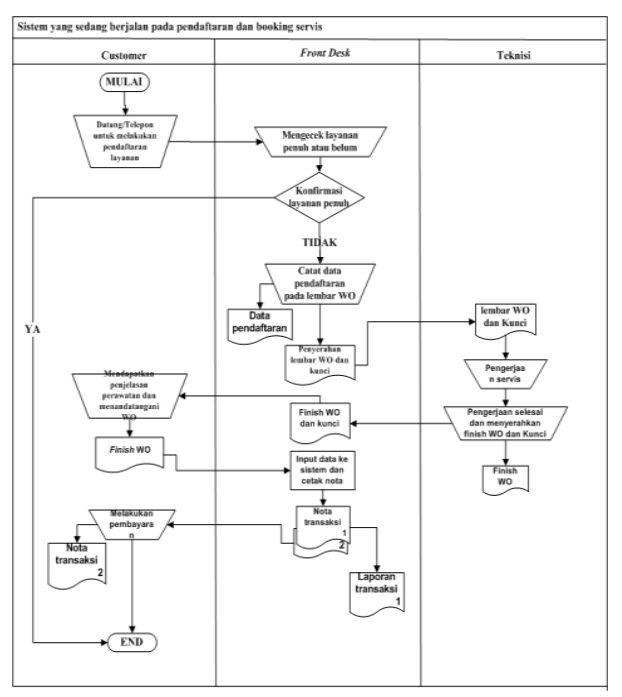

Gambar 2 Alur Sistem Berjalan

\section{B. Pemodelan}

\section{Use Case Diagram}

Usecase adalah gambaran fungsionalitas dari suatu sistem, dimana kebutuhan dari pengguna sistem akan digambarkan sehingga pengguna sistem dapat memahami atau mengerti mengenai fungsi dan kegunaan sistem yang akan dibangun, Use Case Diagram yang diusulkan dapat dilihat pada Gambar 3 berikut

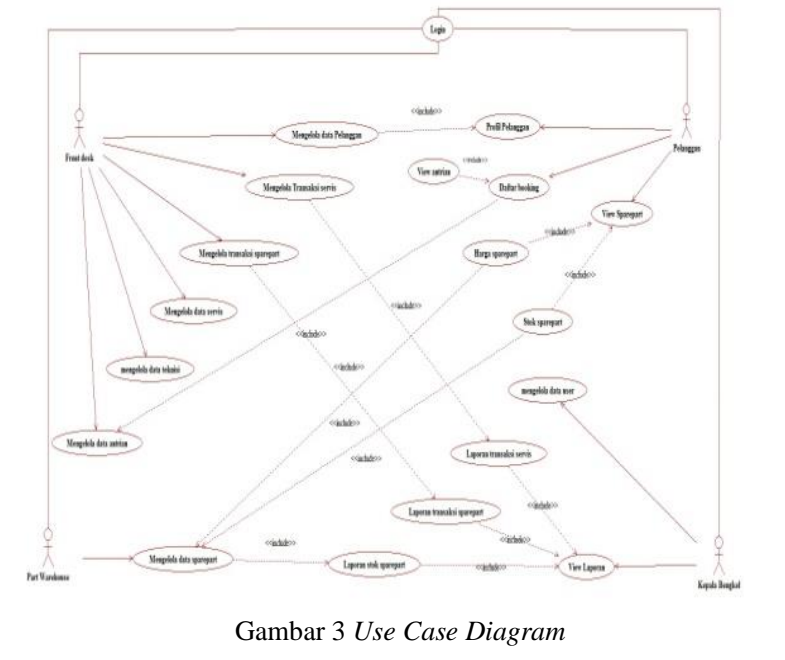




\section{Activity Diagram}

a. Activity Diagram Front Desk

Proses activity diagram front desk menggambarkan aktivitas dari pengguna yaitu front desk untuk melakukan proses pengolahan data pada sistem informasi service motor dapat dilihat pada gambar 4 .

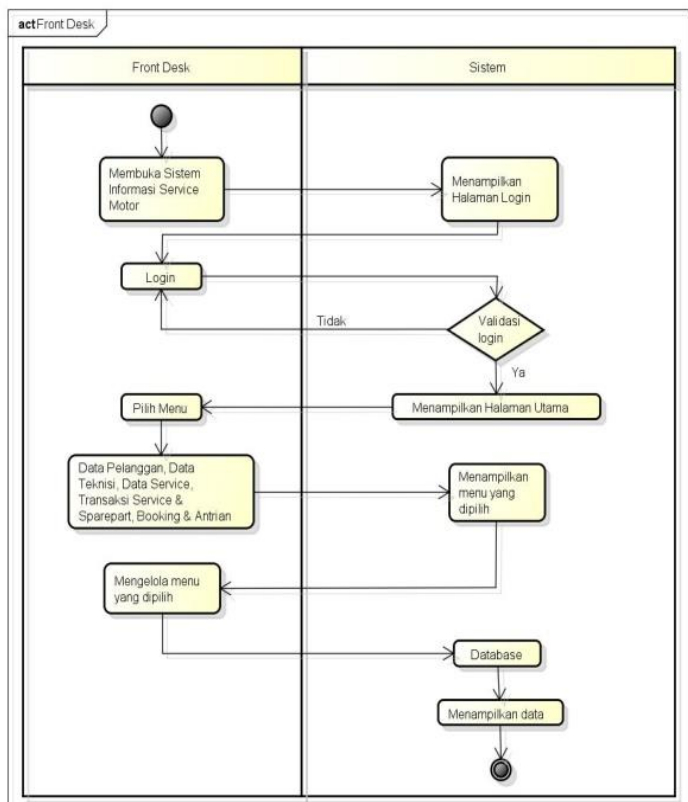

Gambar 4. Activity Diagram Front Desk

\section{b. Activity Diagram Part Warehouse}

Activity diagram part warehouse yang diusulkan dapat dilihat pada gambar 5. Activity Diagram ini menggambarkan aktivitas part warehouse untuk melakukan proses pengolahan data pada sistem informasi service motor.

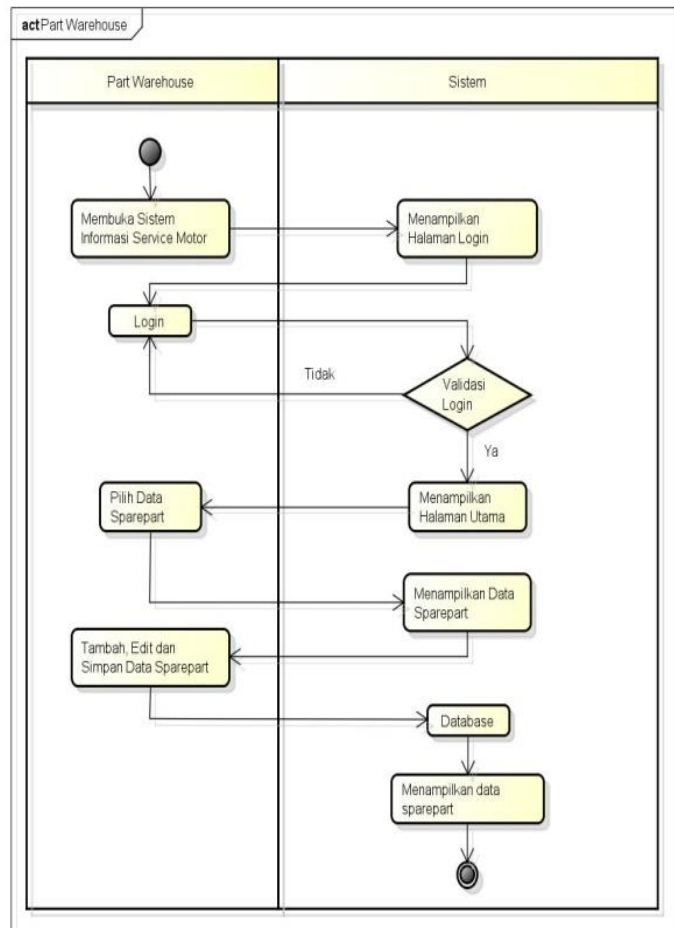

Gambar 5. Activity Diagram Part Warehouse

\section{c. Activity Diagram Kepala Bengkel}

Proses activity diagram kepala bengkel yang diusulkan menggambarkan aktivitas dari pengguna yaitu kepala bengkel untuk melakukan proses pengolahan data pada sistem informasi service motor. Activity Diagram kepala bengkel dapat dilihat pada gambar 6 .

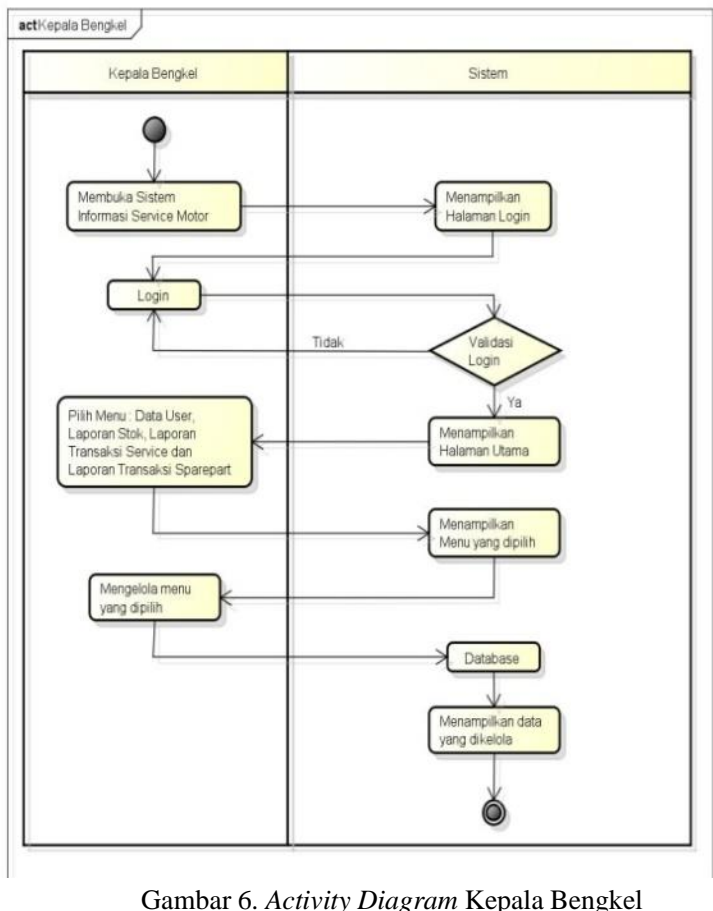

\section{d. Activity Diagram Pelanggan}

Proses activity diagram pelanggan yang diusulkan menggambarkan aktivitas pelanggan untuk melakukan booking service motor dapat dilihat pada gambar 7 .

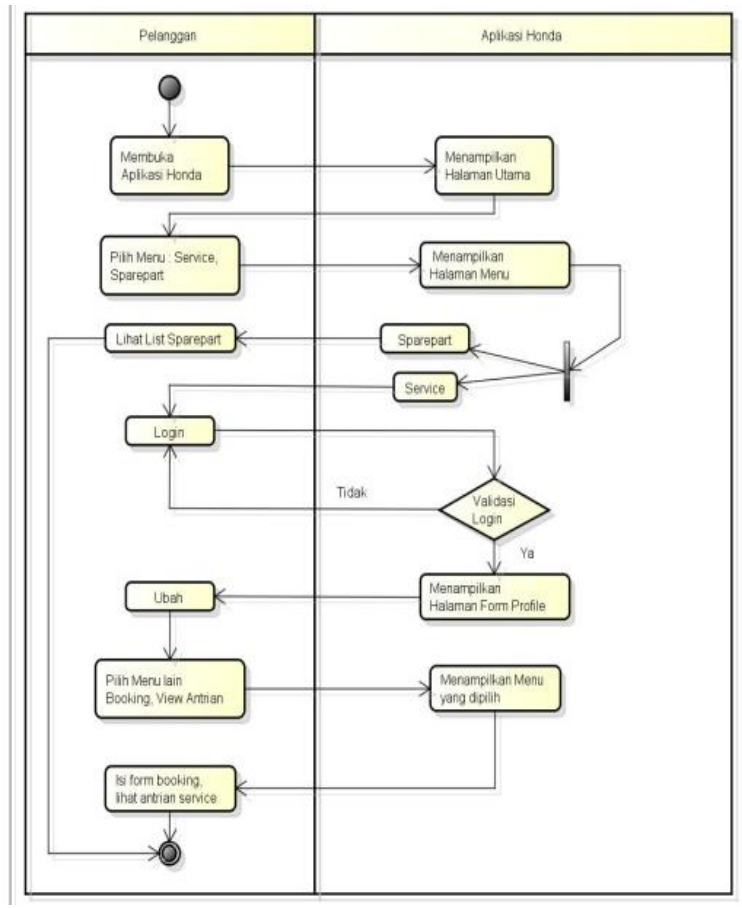

Gambar 7. Activity Diagram Pelanggan 


\section{Class Diagram}

Class diagram menggambarkan struktur dan deskripsi class, package dan objek yang saling terhubung. Class diagram yang dijelaskan pada analisa ini adalah class diagram sistem yang terdapat pada sistem informasi service reservation motor. Adapun class diagram yang diusulkan dapat dilihat pada gambar 8.

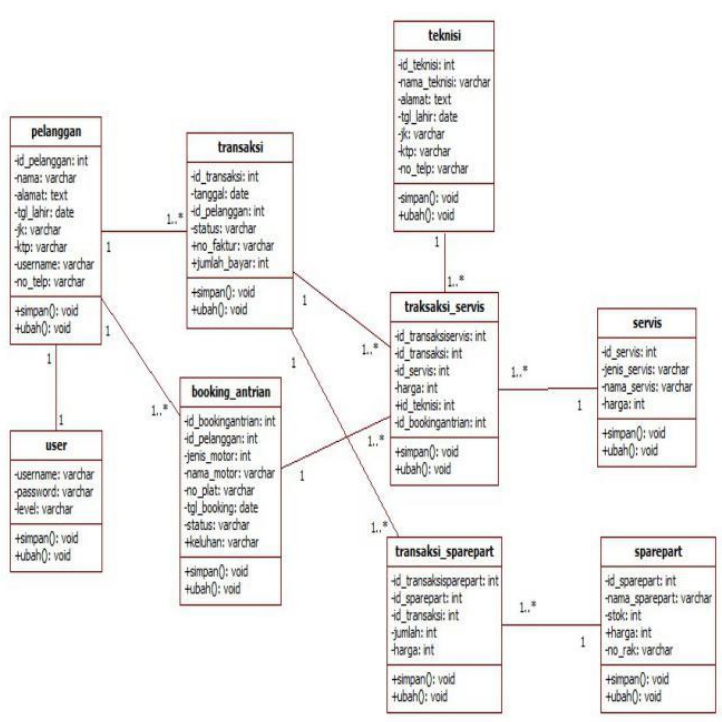

Gambar 8. Class Diagram

C. Antarmuka Sistem (Berbasis Web)

Merupakan halaman sistem informasi service reservation motor yang diakses oleh front desk, partwarehouse dan kepala bengkel.

1. Halaman Login

Antarmuka halaman login user Sistem Service Reservation Motor digunakan untuk autentifikasi user yang berhak menggunakan sistem yaitu terdiri dari front desk, part warehouse dan kepala bengkel. Dimana halaman login diperlihatkan pada gambar 9 .

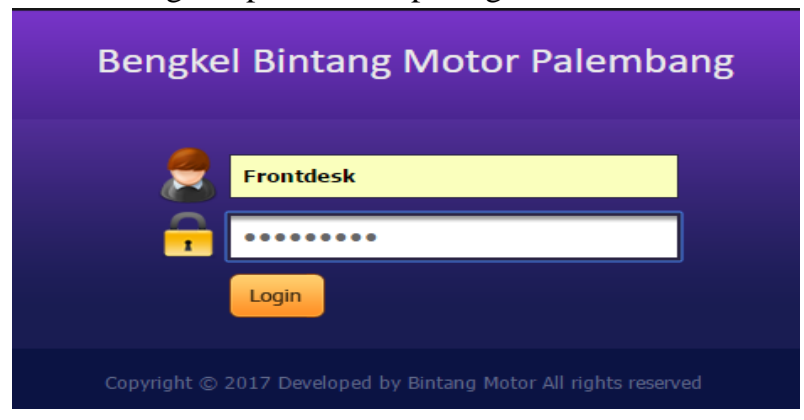

Gambar 9. Halaman Login

\section{Halaman Tambah Pelanggam}

Antarmuka halaman form tambah pelanggan seperti pada Gambar 10, merupakan tampilan halaman form tambah data pelanggan yang dikelola oleh front desk.

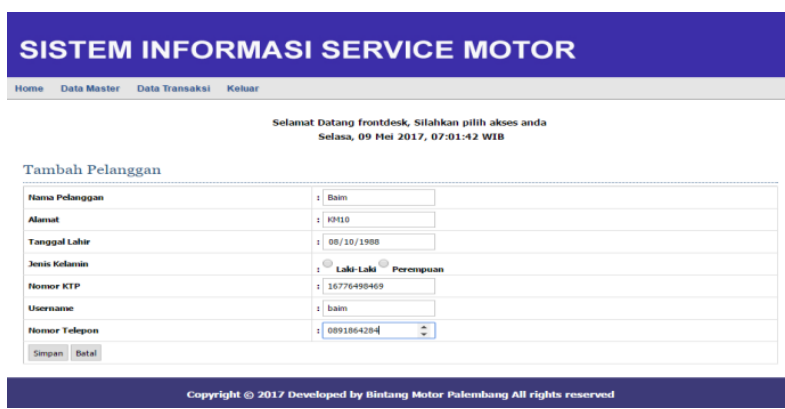

Gambar 10. Halaman Tambah Pelanggan

3. Halaman Booking dan Antrian

Antarmuka halaman booking dan antrian merupakan halaman pemesanan layanan service bagi pelanggan yang datang langsung ke bengkel bintang motor Palembang yang dikelola oleh petugas front desk dapat dilihat pada gambar 11 .

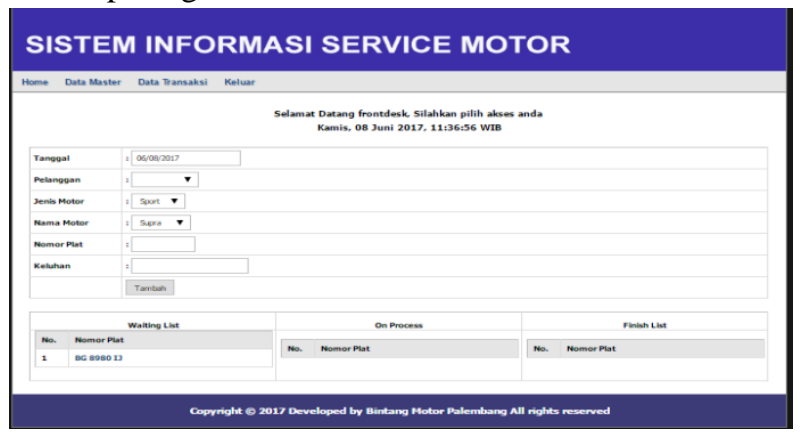

Gambar 11. Halaman Booking dan Antrian

4. Halaman Transaksi Service dan Sparepart

Antarmuka halaman transaksi service dan sparepart dapat dilihat pada gambar 12. Halaman transaksi service dan sparepart merupakan halaman transaksi service dan sparepart yang dikelola oleh petugas front desk.

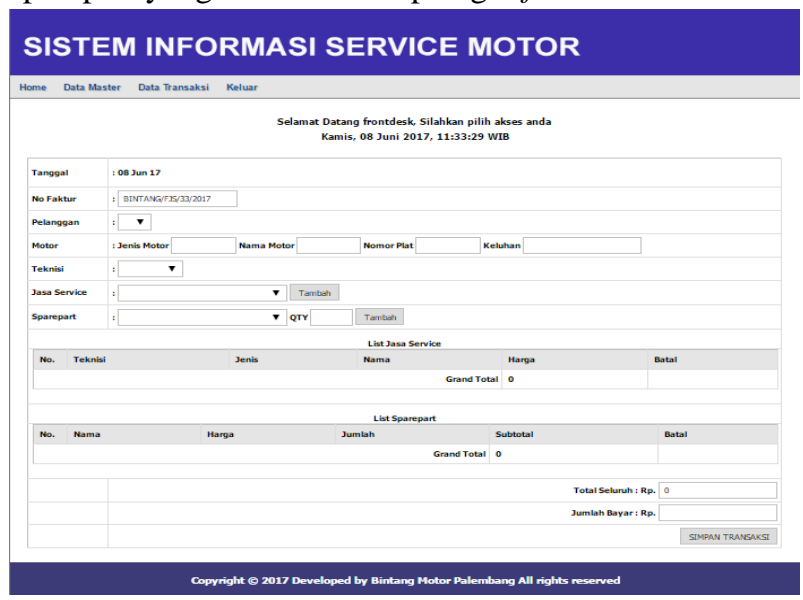

Gambar 12. Halaman Transaksi Service dan Sparepart

5. Halaman Tambah Sparepart

Antarmuka halaman form tambah sparepart merupakan halaman antar muka tambah data sparepart yang dikelola oleh part warehouse, dapat dilihat pada gambar 13. 


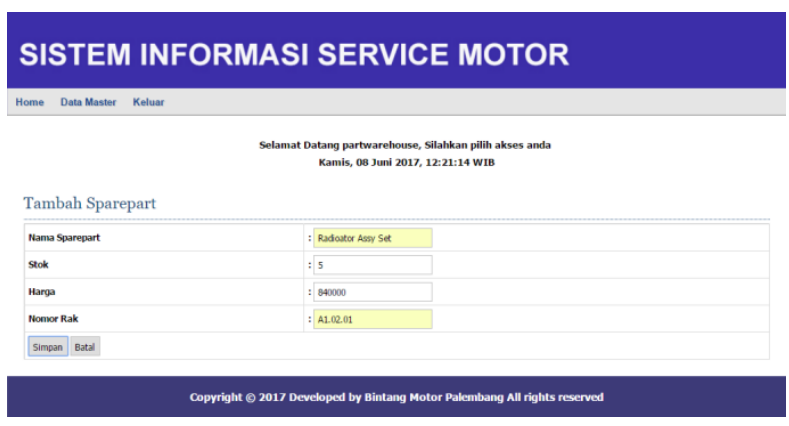

Gambar 13. Halaman Tambah Sparepart

6. Halaman Laporan

Halaman laporan transaksi service merupakan merupakan tampilan hasil dari proses transaksi service yang dikelola oleh kepala bengkel. Adapun halaman laporan dapat dilihat pada gambar 14 .

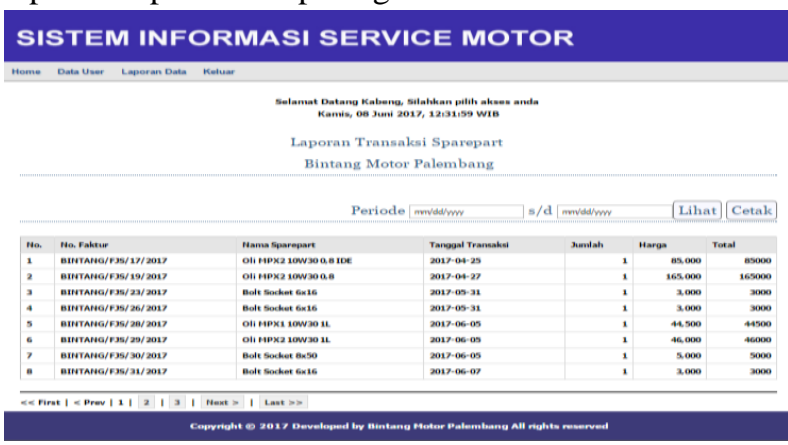

Gambar 14. Halaman Laporan Transaksi Service

\section{Antarmuka Berbasis Android}

Merupakan tampilan halaman pada aplikasi honda bintang yang diperuntukan untuk pengguna yaitu pelanggan bengkel bintang.

\section{Halaman utama}

Halaman utama aplikasi android merupakan rancangan tampilan halaman antarmuka utama pada aplikasi Bintang Motor di android yang akan digunakan untuk pelanggan. Tampilan halaman ini ditunjukkan pada gambar 15 .

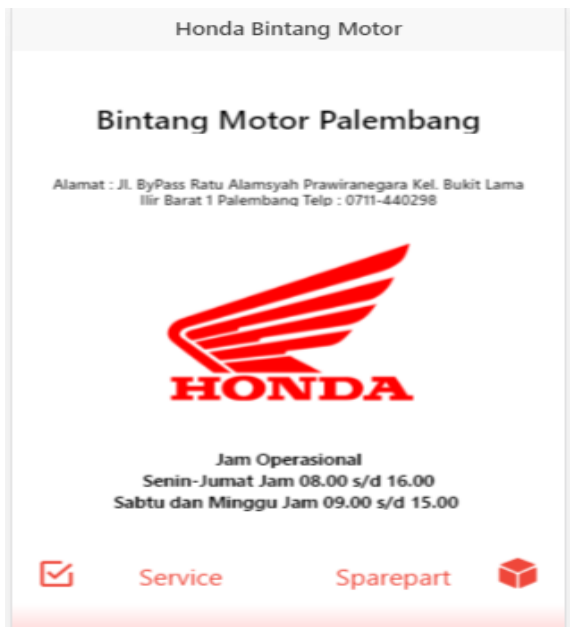

Gambar 15. Halaman Utama Pelanggan

\section{Halaman List Sparepart}

Halaman sparepart merupakan tampilan antarmuka yang menampilkan daftar sparepart yang tersedia di bengkel bintang motor Palembang. Halaman ini dapat dilihat pada gambar 16 .

$$
<\text { Back List Sparepart }
$$

\section{Bintang Motor Palembang}

Alamat : Il. Bypass Ratu Alamsyah Prawiranegara Kel. Bukit Lama
llir Barat 1 Palembang Telp $=0711-440298$

\section{List Sparepart}

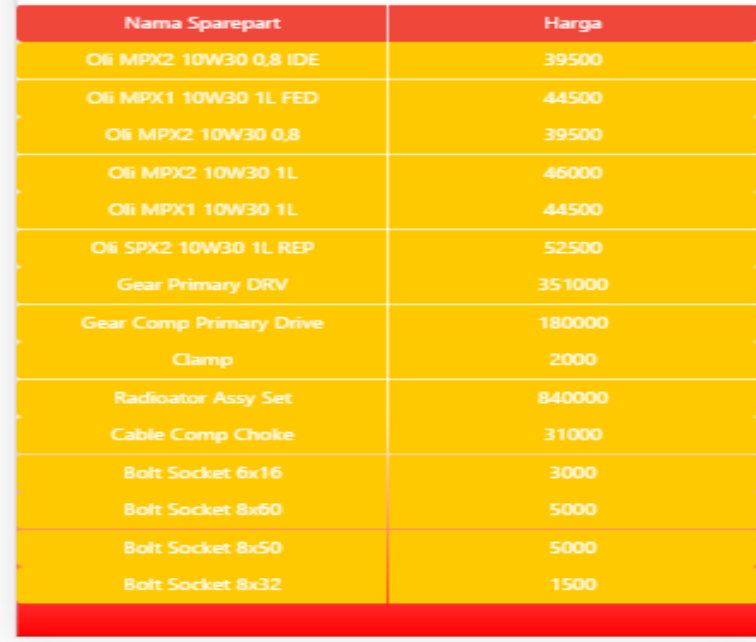

Gambar 16. Halaman List Sparepart

\section{Halaman Booking Service}

Halaman booking service merupakan untuk tampilan antarmuka form booking service untuk pelanggan melalui andorid. Pada menu android ini menampilkan form booking service dengan menginputkan nama pelanggan, jenis motor, nama motor, nomor plat dan tanggal service yang dipilih. Adapun halaman ini dapat dilihat pada gambar 17 .

$$
\text { Booking Service }
$$

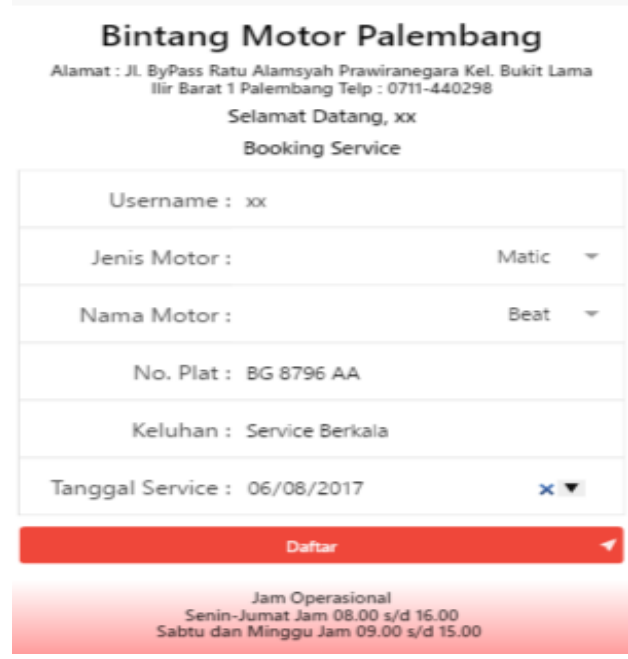

Gambar 17. Halaman Booking Service 
Setelah pelanggan melakukan booking service, maka pelanggan dapat melihat daftar antrian service dengan membuka halaman antrian service, seperti pada gambar 18.

Antrian Service

\section{Bintang Motor Palembang}

Alamat : Jl. Bypass Ratu Alamsyah Prawiranegara Kel.Bukit Lama llir Barat 1 Palembang Telp: 0711-440298

\section{Antrian Service}

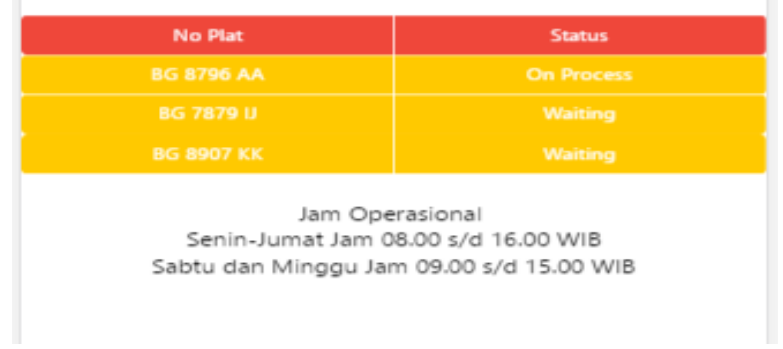

Gambar 18. Halaman Antrian Service

\section{KESIMPULAN}

Berdasarkan hasil pembahasan dari penelitian sistem informasi service reservation motor berbasis android pada bengkel bintang motor Palembang, maka dapat disimpulkan bahwa sistem yang dibangun dapat melakukan pemesanan layanan service motor melalui android serta dapat melihat antrian service secara realtime, dapat melihat harga sparepart yang tersedia pada bengkel bintang motor Palembang. Untuk sistem informasi service reservation motor yang dapat mengolah data service, data teknisi, data pelanggan, data user, data sparepart, data booking \& antrian serta mengolah data transaksi service dan sparepart. Dengan adanya sistem ini diharapkan dapat mempermudah pelanggan dalam hal pemesanan layanan service motor tanpa harus datang langsung kebengkel serta dapat membantu dalam hal pengolahan laporan bengkel.

\section{REFERENCES}

[1] Yulirianto, Asep. 2014. "Jurus Kilat Jadi Montir Profesional Secara Otodidak”. Jakarta Timur : Laskar Askara.

[2] Nugroho, Reza Fajar, dkk. 2016. "Perancangan dan Implementasi Sistem Reservasi Servis Mobil Berbasis Website". E-Proceeding of Applied Science : Vol 2, No 3.

[3] Sucipto, Adi, dkk. 2018. "Penerapan Aplikasi Mobile Information Karimun Island Menggunakan Ionic Framework". JTET (Jurnal Teknik Elektro Terapan): Vol 7 No 1.

[4] Tompoh, Jon Forman, dkk. 2016. "Rancang Bangun Aplikasi Pemesanan Menu Makanan Berbasis Android". E-journal Teknik Informatika: Vol 9 No 1.

[5] Ramadhani, Anis. 2013. "Jurus Rahasia Pintar Menguasai Android Untuk Pemula”. Jakarta : Kir Direction.

[6] Supardi, Yuniar. 2015. "Belajar Coding Android bagi Pemula". Jakarta : Elex Media Komputindo.

[7] http://cordova.apache.org/docs/en/latest/guide/overview/index.ht $\underline{\mathrm{ml}}$

[8] Julisman, Agung. 2015. "Bikin Aplikasi Andriod dengan Anguler Mobile Mongo DB”. Yogyakarta : Lokomedia.

[9] Rosa, A.S dan M. Shalahuddin. 2011. "Modul Pembelajaran Rekayasa Perangkat Lunak (Terstruktur dan Berorientasi Objek)". Bandung : Modula.

[10] Sholiq. 2010. "Analisis dan Perancangan Berorientasi Objek". Bandung : CV. Muara Indah Bandung.

[11] R.S.Pressman. 2012. "Rekayasa Perangkat Lunak”. Yogyakarta : Andi. 